\title{
Controlling the Parameters of Process of Drilling Wells Using Mathematical Modeling
}

\author{
Dairbayeva Gullazata", a Kabylzhan Ainur ${ }^{2, b}$ \\ ${ }^{1}$ flat 40, Klochkova 89, Almaty, Kazakhstan \\ 2flat 2, Tlendieva 258a, Almaty, Kazakhstan \\ alazat-dairbayeva@mail.ru, bainura1.93@gmail.com
}

Keywords: Drilling of wells, Flushing-out, Drilling speed by rock bit, Pressure, Mathematical model, Regression analysis.

\begin{abstract}
The process of drilling of wells using mathematical modeling is considered in this paper. Mathematical models of deepening and flushing of wells are used to describe the drilling process. Mechanical speed of drilling bedrock by bit is described by the equation proposed by M.G. Bingham [1]. A complete mathematical model of penetration rate (deepening), taking into account the hydraulic parameters, is investigated. This model obtained by applying the method of least squares and regression analysis. The software for deepening and flushing of wells models are worked out. The numerical calculations for mechanical speed of drilling are conducted. A comparative analysis of the drilling experimental and computational data is carried out. Mathematical model of the hydraulic flushing of wells based on the finding total loss of pressure of drilling fluid in individual sections of the well. The results of calculating the total pressure loss are presented. By those results the type and capacity of the mud pump can be determined. Knowing the speed and mechanical pressure loss we can control drilling process.
\end{abstract}

\section{Introduction}

The drilling process takes the most important place in the construction of wells and it is a complex and difficult process. The main advantages of drilling under control are improving the parameters of the drilling process, controlling the main parameters of system, such as back pressure, the density, the volume of flushing fluid, the power of the drilling, the pressure loss at various sections of the well. The process of drilling wells consists of two main stages: the process of deepening and flushing wells process.

\section{Mathematical Model of the Deepening Process}

The ratio, which determines the mechanical speed of drilling (penetration rate) of well by bit with a certain amount of flushing fluid, takes the form proposed by M.G. Bingham:

$$
v_{m}=K G^{\delta} n^{\alpha}
$$

where, $K, \delta$ and $\alpha$ - parametric ratios [1]. However, hydraulic parameters are not considered in this model.

Let's consider a more complete mathematical model of penetration rate with taking hydraulic parameters into account [6]:

$$
v_{m}=\mathrm{f}\left(\mathrm{G}, \mathrm{n}, \mathrm{N}_{b}\right)
$$

where, $\mathrm{G}$ - axial load on bit, $\mathrm{N}_{\mathrm{b}}=\mathrm{f}\left(\mathrm{Q}, \mathrm{P}_{\mathrm{b}}\right)$ - hydraulic power applied to the bit, $\mathrm{Q}$ - mud flow rate.

It is obvious that the variable $\mathrm{N}_{\mathrm{b}}$ should enter into the equation of the function in Eq. 1 as a directly proportional component with the coefficient or with an exponent, which provides the necessary slope 
and bending of curve of function $v_{m}$. This is because the more amount of liquid supplied to the bottom hole, the better its purification [6]. Bottom hole cleaning is an important factor that influences to the mechanical speed of drilling the rock by bit. The bad cleaning of bottom hole from the drill cuttings entails regrinding, the excess energy consumption to work and increasing time limits of well construction in general.

To build a complete mathematical model is necessary to derive a formula $v_{m}=\mathrm{f}\left(\mathrm{G}, \mathrm{n}, \mathrm{N}_{\mathrm{b}}\right)$ using the least squares method [3].

To do this, firstly multivariate regression analysis is carried out [2]. Let's show applying a regression analysis of the experimental data in a Table 1 . This approach allows us to replace the experimental data with approximating mathematical equation with sufficient accuracy and calculate the values of function for those arguments, which are between the values in the Table 1 and going beyond its boundaries.

Table 1. Experimental data LLC "Burgaz".

\begin{tabular}{|l|l|l|l|}
\hline$v_{m}[\mathrm{~m} / \mathrm{s}]$ & $G[\mathrm{kN}]$ & $n$ & $N_{b}$ \\
\hline 1 & 0 & 0 & 36 \\
\hline 6,1 & 58 & 28 & 74 \\
\hline 12,65 & 116 & 30 & 148 \\
\hline 17,55 & 146 & 36 & 222 \\
\hline 19,75 & 152 & 42 & 296 \\
\hline 20,95 & 156 & 45 & 370 \\
\hline 21,6 & 158 & 46 & 444 \\
\hline 21,9 & 161 & 46 & 518 \\
\hline 22,7 & 164 & 48 & 592 \\
\hline
\end{tabular}

By determination of the method of least squares, the difference $\left(v_{m i}-V_{m i}\right)^{2}$ between experimental (tabulated) values $\mathrm{v}_{\mathrm{m}}$ and values of approximating function $\mathrm{V}_{m}$ should be minimal:

$$
\left(\mathrm{v}_{\mathrm{m} 1}-\mathrm{V}_{\mathrm{m} 1}\right)^{2}+\left(\mathrm{v}_{\mathrm{m} 2}-\mathrm{V}_{\mathrm{m} 2}\right)^{2}+\cdots+\left(\mathrm{v}_{\mathrm{mn}}-\mathrm{V}_{\mathrm{mn}}\right)^{2}=\min
$$

Task of approximation the function $v_{m}$ is formulated as follows: for the function $v_{m}$ given by Table 1 , to find the function $V_{m}$ in power form so that the sum of the squares Eq. 3 will be minimal. Since the dependence $v_{m}=\mathrm{f}\left(\mathrm{G}, \mathrm{n}, \mathrm{N}_{\mathrm{b}}\right)$ is a power function (geometric regression), the approximating function must have the form:

$$
\mathrm{V}_{\mathrm{m}}(\mathrm{K}, \delta, \alpha, \mathrm{m})=\mathrm{KG}^{\delta} \mathrm{n}^{\alpha} \mathrm{N}_{\mathrm{b}}^{\mathrm{r}}
$$

where, $\mathrm{K}$ - the coefficient of proportionality (drillability), $\delta, \alpha, \mathrm{r}$ - exponents depending on the type of bit and the quality of cleaning of bottom hole.

The purpose of regression analysis is to define the coefficient $\mathrm{K}$ and exponents $\delta, \alpha$ and $\mathrm{r}$ in Eq. 4 . Then the sum of the squares of the differences Eq. 3 in expanded form:

$$
\sum_{\mathrm{i}=1}^{9}\left[\mathrm{v}_{\mathrm{mi}}-\mathrm{V}_{\mathrm{mi}}\left(\mathrm{K}, \mathrm{G}, \delta, \mathrm{n}, \alpha, \mathrm{N}_{\mathrm{b}}, \mathrm{r}\right)\right]^{2}=\mathrm{F}\left(\mathrm{K}, \mathrm{G}, \delta, \mathrm{n}, \alpha, \mathrm{N}_{\mathrm{b}}, \mathrm{r}\right) \text {. }
$$

Finding the approximating value of function $\mathrm{V}_{m}(\mathrm{~K}, \delta, \alpha, \mathrm{r})$ is complicated by exponents $(\delta, \alpha$ и $\mathrm{r})$. To replace $V_{m}$ to the linear form, take logarithms of both sides:

$$
\ln V_{\mathrm{m}}=\ln \mathrm{K}+\delta \ln \mathrm{G}+\alpha \ln \mathrm{n}+\operatorname{rnn}_{\mathrm{b}} \text {. }
$$

Since the calculated function $\mathrm{V}_{m}$ is approximating to the table function $v_{m}$, the function $\ln \mathrm{V}_{m}$ will be approximating to the function $\ln v_{m}$.

Let us introduce new variables and symbols: 


$$
\mathrm{k}=\ln \mathrm{K}, \mathrm{u}=\ln \mathrm{G}, \varphi=\ln \mathrm{n}, \mathrm{w}=\ln \mathrm{N}_{\mathrm{b}} \text {. }
$$

Then from Eq. 6 follows that $\ln \mathrm{V}_{m}$ will be a function of the argument $\mathrm{k}, \mathrm{u}, \varphi$ and $\mathrm{w}$. We obtain: $\mathrm{V}=$ $\mathrm{k}+\delta \mathrm{u}+\alpha \varphi+\mathrm{rw}$ by denoting $\mathrm{V}=\ln \mathrm{V}_{m}$. Thus, the task of finding the value of an approximating power function $V_{m}$ reduced to the problem of finding the value of a linear function $\mathrm{V}$. Accordingly, we denote $\mathrm{v}=\ln v_{m}$. Therefore, least square method to $\ln v_{m}$ and approximating function $\ln \mathrm{V}_{m}:\left(\ln v_{m 1}-\right.$ $\left.\ln V_{m 1}\right)^{2}+\left(\ln v_{m 2}-\ln V_{m 2}\right)^{2}+\cdots+\left(\ln v_{m i}-\ln V_{m i}\right)^{2}=\min$.

Since $\sum_{i=1}^{9}\left(\ln v_{m i}-\ln V_{m i}\right)^{2}=\sum_{i=1}^{9}\left(\mathrm{v}_{i}-\mathrm{V}_{i}\right)^{2}$, then we will look for a minimum of the following function: $\sum_{i=1}^{9}\left(\mathrm{v}_{i}-\mathrm{V}_{i}\right)^{2}=\sum_{i=1}^{9}\left(\mathrm{v}_{i}-\left(\mathrm{k}+\delta u_{i}+\alpha \varphi_{i}+\mathrm{r} w_{i}\right)\right)^{2}=H(k, \delta, \alpha, r)$.

To find the necessary condition of a minimum of $\mathrm{H}$, we calculate the partial derivatives over the variables $\mathrm{k}, \delta, \alpha, \mathrm{r}$ and equate them to zero.

$$
\begin{aligned}
& \sum_{i=1}^{9}\left[v_{i}-\left(k+\delta u_{i}+\alpha \varphi_{i}+r w_{i}\right)\right](-1)=0, \\
& \sum_{i=1}^{9}\left[v_{i}-\left(k+\delta u_{i}+\alpha \varphi_{i}+r w_{i}\right)\right]\left(-u_{i}\right)=0, \\
& \sum_{i=1}^{9}\left[v_{i}-\left(k+\delta u_{i}+\alpha \varphi_{i}+r w_{i}\right)\right]\left(-\varphi_{i}\right)=0, \\
& \sum_{i=1}^{9}\left[v_{i}-\left(k+\delta u_{i}+\alpha \varphi_{i}+r w_{i}\right)\right]\left(-w_{i}\right)=0,
\end{aligned}
$$

where, $\mathrm{v}_{i}=\ln v_{m i}, u_{i}=\ln G_{i}, \varphi_{i}=\ln n_{i}, w_{i}=\ln N_{b i}$, and the values $v_{m i}, G_{i}, n_{i}, N_{b i}$ are given in Table 1.

The system in Eq. 8 is a linear system with respect to $\mathrm{k}, \delta, \alpha$ and r. Knowing its solution $\mathrm{k}, \delta, \alpha$ and $\mathrm{r}$ the approximating function $\mathrm{V}_{m}=\mathrm{KG}^{\delta} \mathrm{n}^{\alpha} \mathrm{N}_{b}^{r}$ can be found.

Program for Calculating the Optimal Parameters of the Mechanical Drilling Process. As shown in previous paragraph the approximating function has a power form: $\mathrm{V}_{m}=\mathrm{KG}^{\delta} \mathrm{n}^{\alpha} \mathrm{N}_{b}^{r}$, but the coefficient $\mathrm{K}$ and indexes of power $\delta, \alpha$ and $\mathrm{r}$ are unknown. Here is computational algorithm for finding approximating function $\mathrm{V}_{m}$.

1. Construction of an auxiliary approximating function $\mathrm{V}$.

We form a new Table 2, using the data in Table 1 . In Table 2 instead of values $v_{m}, \mathrm{G}, \mathrm{n}$ and $N_{b}$ will be their logarithms $\mathrm{v}=\ln v_{m}, \mathrm{u}=\ln G, \varphi=\ln n, w=\ln N_{b}$.

$\mathrm{V}$ is linear following from regression analysis [2]: $\mathrm{V}=\mathrm{k}+\delta \mathrm{u}+\alpha \varphi+\mathrm{rw}$, where we use the notation Eq. $8, \mathrm{k}=\ln (\mathrm{K})$.

2. Creating and solution of the linear system Eq. 8.

Applying the method of least squares to $\mathrm{v}=\ln v_{m}$ and auxiliary approximating function $\mathrm{V}=\ln \mathrm{V}_{m}$, compose the linear system in Eq. 8 with respect to the parameters $\mathrm{k}, \delta, \alpha, \mathrm{r}$, using the data in Table 2.

Then we numerically solve the system Eq. 8 and calculate the ratio $K=\exp (\kappa)$.

3. Calculation of the approximating function $V_{m}$.

Substituting the values of $\mathrm{K}, \delta, \alpha$ and $\mathrm{r}$, we find the function $\mathrm{V}_{m}=\mathrm{KG}^{\delta} \mathrm{n}^{\alpha} \mathrm{N}_{b}^{r}$, which is the regression equation.

4. The comparative analysis of table $v_{m}$ and approximate $\mathrm{V}_{m}$ values.

The numerical implementation of the model of the mechanical drilling process was done using the programming language $\mathrm{C \#}$.

Here is the main interface screen of program for controlling the drilling process - Fig. 1 . 


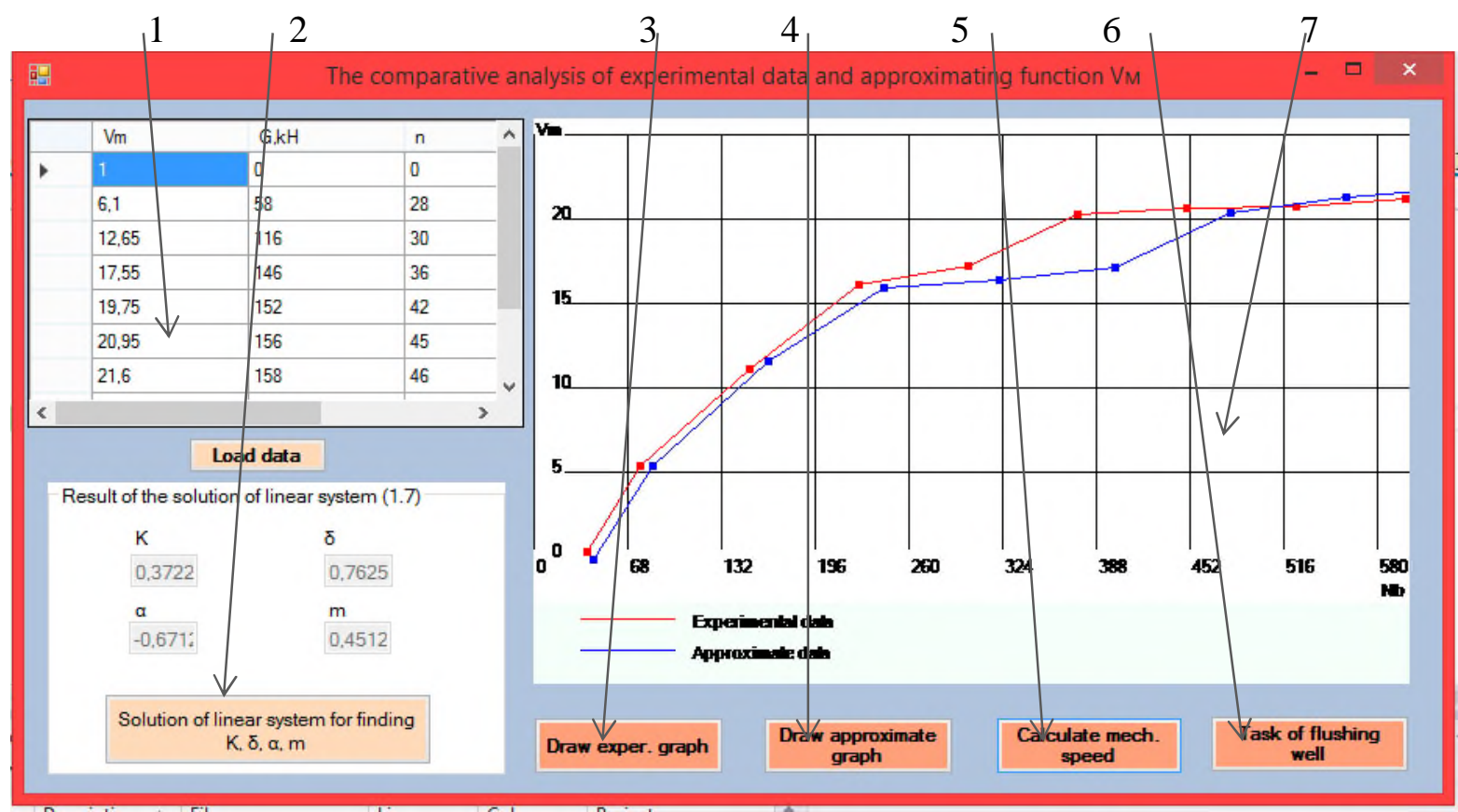

Fig. 1 The main window of software.

The following buttons are indicated here:

1 - experimental data loaded from file;

2 - button for solving linear system in Eq. 8;

3 - button to draw the graph of the experimental data;

4 - button to draw the graph of the approximate function $V_{m}$;

5 - button, which opens an another window, which shown in Fig. 2;

6 - button to open a window for the flushing well task;

7 - field for drawing graph.

We can draw graphs and compare the table and approximate data after we have found the parameters $\mathrm{k}, \delta, \alpha$ and $\mathrm{r}$ in the program, which shown in Fig. 1.

Note that the graphs of approximate and experimental data are close, so we can continue to use the founded parameters $\mathrm{K}, \delta, \alpha$ and $\mathrm{r}$ for other values of $\mathrm{G}, \mathrm{n}$ and $\mathrm{N}_{\mathrm{b}}$.

Calculation of mechanical speed $v_{m}$ for the new values of $\mathrm{G}, \mathrm{n}$ and $\mathrm{N}_{\mathrm{b}}$ is shown in Fig. 2.

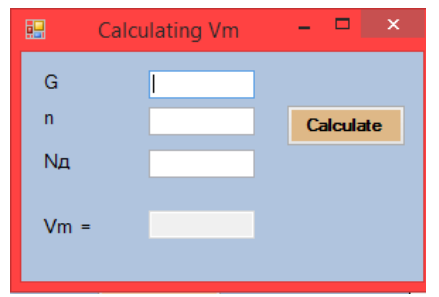

Fig. 2 Calculation of mechanical speed.

\section{Mathematical Model of Hydraulic Flushing of Well}

One of the main stages in the process of drilling is flushing the well using a drilling fluid. Flushing is used to remove drilling cuttings from bottom hole, for deepening, cooling and lubrication the drilling tool. The main components of the equation of flushing wells are flushing pressure $P$ and mud flow rate 
$Q$. Therefore, it is important to understand that the main task is to control the pressure at the inlet of the well. To control the standpipe pressure is necessary to determine how much pressure has to be at each section of pipe.

When we have the pressure loss along the pipeline with identical section, the flow velocity $V$ will be equal to the kinetic energy and will be constant. In this case, the static pressure loss is calculated according to the formula [4]:

$$
\Delta \mathrm{p}=\lambda \frac{\mathrm{L}}{\mathrm{d}} \mathrm{V}^{2} \frac{\rho}{2}-\text { Darcy }- \text { Weisbach equation, }
$$

where, $\Delta p$ - pressure loss, $L$ - section length, $d$ - diameter of pipe, $V$ - flow velocity, $\lambda$ - hydraulic friction coefficient, $\rho$ - liquid density.

Loss of pressure of drilling fluid, generated by the pump drill, calculated for each homogeneous section separately in flushing well process. Then, the total loss of pressure is defined as the sum of all pressure losses on all sections of well. In rotary drilling the pressure in well inlet, i.e. standpipe pressure $P_{c}$ calculated as the sum of the hydrostatic pressure of the liquid column $P_{h s}$ and pressure losses on all elements of the $\sum \Delta P_{i}$ :

$$
\mathrm{P}_{c}=\mathrm{P}_{\mathrm{hs}}+\sum \Delta \mathrm{P}_{\mathrm{i}}=\mathrm{P}_{\mathrm{hs}}+\Delta \mathrm{P}_{\mathrm{st}}+\Delta \mathrm{P}_{\mathrm{p}}+\Delta \mathrm{P}_{\mathrm{t}}+\Delta \mathrm{P}_{\mathrm{wp}}+\Delta \mathrm{P}_{\mathrm{b}}+\Delta \mathrm{P}_{\text {was }}+\Delta \mathrm{P}_{\mathrm{as}} .
$$

The following components of the pressure loss $[5,6]$ are defined in rotary drilling: $\Delta P_{s t}-$ in the surface trim, $\Delta P_{p}$ - in the drill pipe, $\Delta P_{t}-$ in couplings and tool joints, $\Delta P_{w p}-$ in the weighted drill pipe, $\Delta P_{b}$ - in the drilling bit, $\Delta P_{w a s}$ - in annular space between the weighted drill pipe and the borehole wall, $\Delta P_{a s}$ - in annular space between the drill pipe and the borehole wall, $P_{h s}-$ the hydrostatic pressure of the liquid column.

Eq. 10 is the main equation of the flushing of well process.

Mud flow rate $Q$ is determined by the speed $V$ of flow motion. Based on the results of calculation of the drilling fluid flow and pressure loss in each section, we can calculate minimum required hydraulic power of drilling pump: $N=P_{\mathrm{c}} Q$.

According to the total losses we can select the type of mud pump and according to filing - full capacity.

The complete mathematical model of the hydraulic flushing of wells will be as follows:

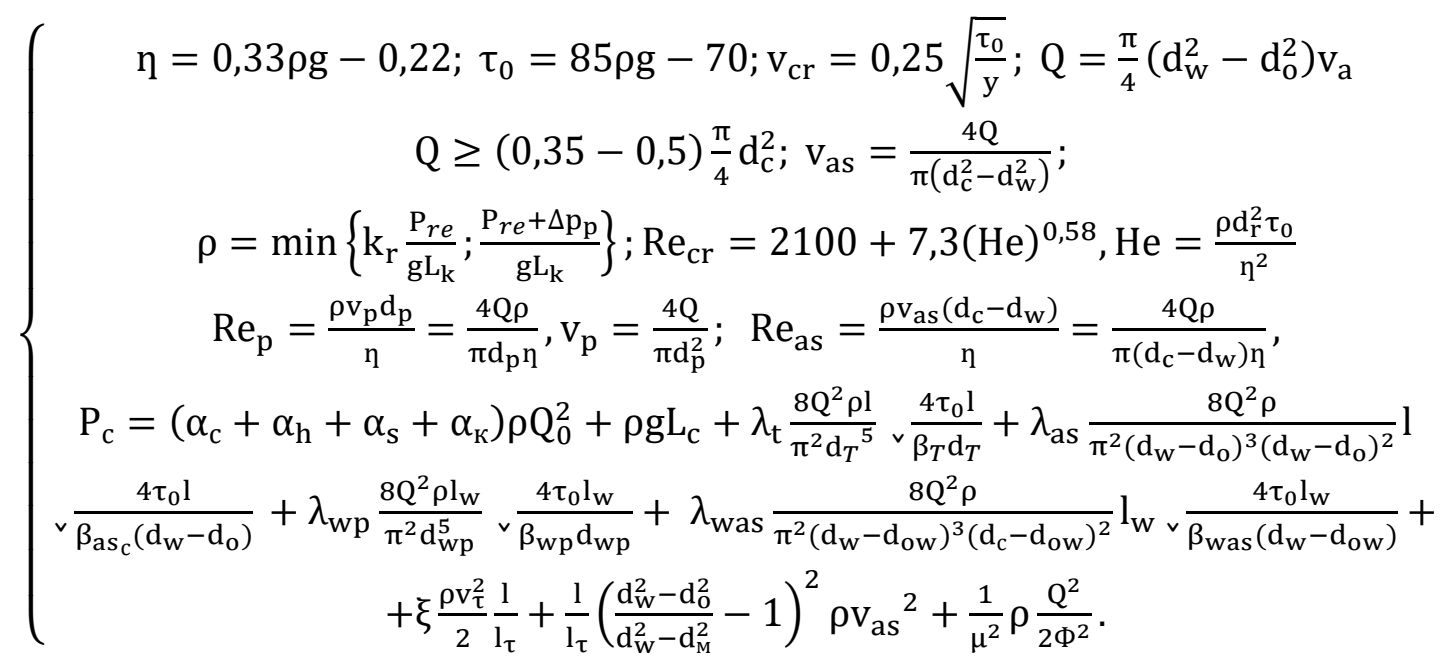

Restrictions:

$\rho<\frac{\mathrm{P}_{g r}-\sum\left(\Delta \mathrm{p}_{a s}\right)-(1-\varphi) \rho_{a s} g L_{\Pi}}{\varphi g L_{p}}, \varphi=\frac{Q}{\frac{\pi}{4} v_{\mathrm{M}} d_{o}^{2}+Q} ;$

$k \frac{P_{r e+1,5}}{L_{c}} \leq \rho \leq k \frac{P_{r e}+3,5}{L_{c}} ; \quad k \frac{Q}{\left(\mathrm{~d}_{w}^{2}-\mathrm{d}_{o}^{2}\right)} \geq 0,4 ; \quad P_{c} \leq P_{n d} ; k \cdot \Delta P_{b} \cdot Q=$ const.

In the hydraulic model following symbols are used: 
$\eta$ - plastic (dynamic) viscosity of the fluid $[\mathrm{Pa} \cdot \mathrm{s}]$;

$\rho$ - flushing fluid density $\left[\mathrm{kg} / \mathrm{m}^{3}\right]$;

$g-$ acceleration of gravity $=9,8\left[\mathrm{~m} / \mathrm{s}^{2}\right]$

$\tau_{0}-$ dynamic shear stress of the liquor $[\mathrm{Pa}]$;

$v_{c r}-$ critical speed of fluid flow $[\mathrm{m} / \mathrm{s}]$;

$\gamma-$ specific gravity of liquor $\left[\mathrm{kg} / \mathrm{m}^{3}\right]$;

$Q-$ drilling mud circulation rate $\left[\mathrm{m}^{3} / \mathrm{s}\right]$;

$\mathrm{d}_{\mathrm{w}}$ - diameter of well (bit) $[\mathrm{m}]$;

$\mathrm{d}_{o}-$ he outer diameter of the drill pipe $[\mathrm{m}]$;

$v_{\mathrm{a}}, v_{a s}, v_{p}$ - velocity of liquor movement in the annulus of the well and in the pipes $[\mathrm{m}]$;

$\mathrm{Re}_{\mathrm{cr}}, \mathrm{Re}_{\mathrm{as}}, \mathrm{Re}_{\mathrm{p}}$ - critical Reynolds number, Reynolds number in the annulus, Reynolds number in the pipes;

$\mathrm{k}_{\mathrm{r}}$ - reserve ratio;

$\mathrm{P}_{r e}$ - reservoir pressure $[\mathrm{Pa}]$;

$\mathrm{L}_{\mathrm{r}}$ - depth of the reservoir with a maximum gradient of the roof of reservoir pressure $[\mathrm{m}]$;

$\mathrm{L}_{c}$ - occurrence reporting layer soles depth $[m]$;

$\alpha_{c}, \alpha_{h}, \alpha_{s}, \alpha_{k}$ - coefficients of hydraulic resistance in the riser, the drilling sleeve (hose), swivel, kelly;

$\mathrm{P}_{\mathrm{c}}$ - the pressure in the riser $[\mathrm{Pa}]$.

Software Implementation of A Mathematical Model of the Hydraulic Flushing of Well. The window, which is shown in Fig. 3, will be opened after clicking the button 6 from previous paragraph.

In this window, user selects the type of flow: turbulent or structured, also sets the basic unchangeable parameters to calculate the total pressure loss.

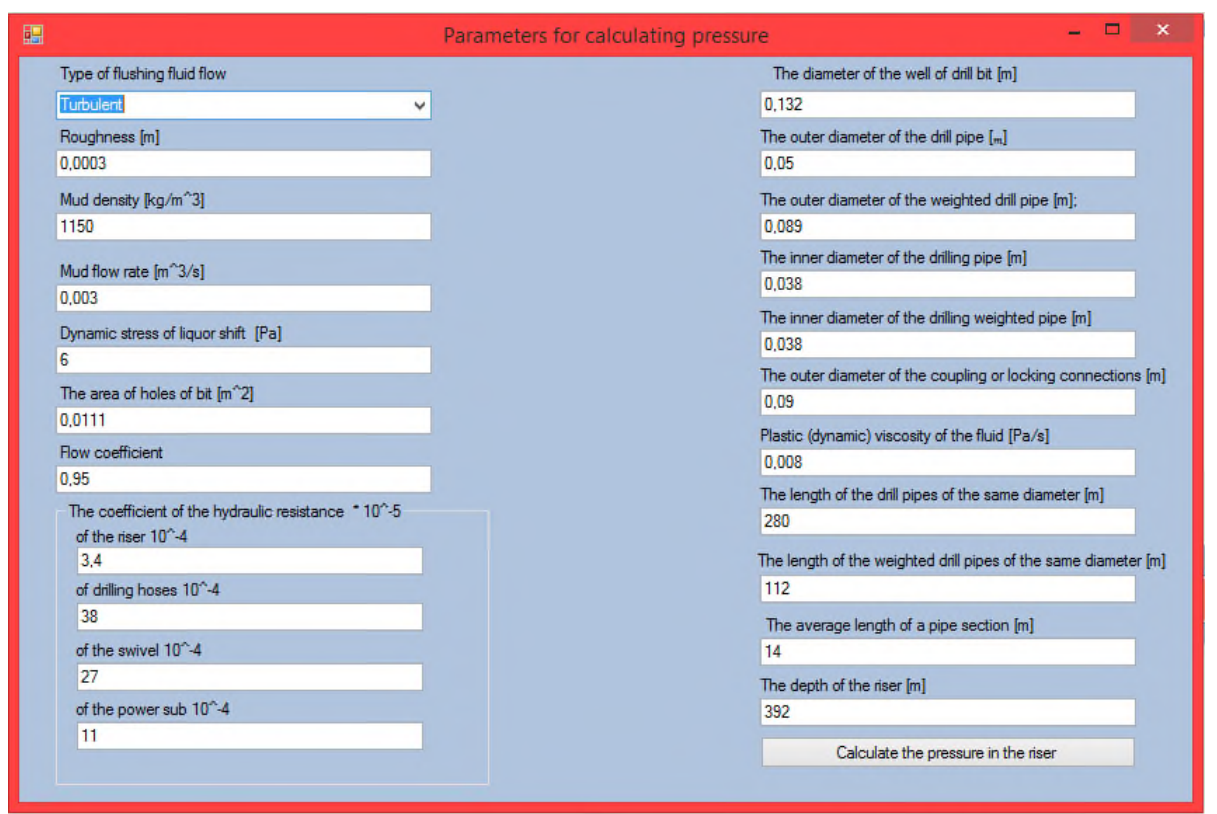

Fig. 3 Window for entering the parameters to calculate the standpipe pressure. 


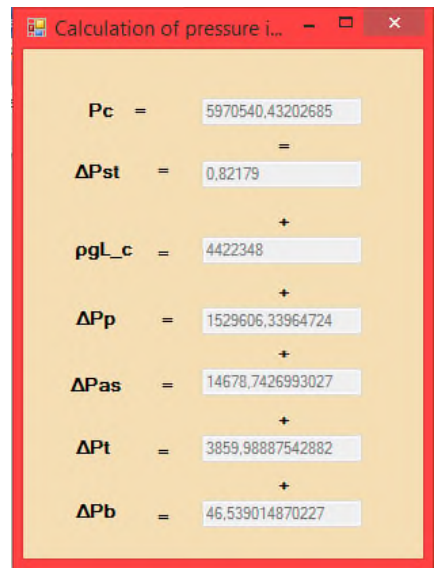

Fig. 4 Window to display the results of calculation of the total pressure loss $\mathrm{P}_{\mathrm{c}}$.

After entering data and clicking the "Calculate pressure in the riser" by user, the window in Fig. 4 will appear. In the new window will be the values of pressure loss and total loss $\mathrm{P}_{c}$ that have been numerically calculated by a mathematical model of Eq. 11 .

\section{Summary}

There computational algorithm for finding the parametric coefficients was developed based on the complete mathematical model of mechanical speed of drilling. The model allows calculating the speed for any mechanical drilling data. A comparative analysis between the experimental and computational data is done. The total loss of drilling fluid pressure is calculated using a mathematical model of flushing of well. Using above mathematical models we can carry out the control of the process of drilling wells.

\section{References}

[1] M. G. Bingham, Problems of drill ability rocks, Forest Protection series Drilling, All-Russian Scientific Research Institute of organization, management and economy of the oil and gas industry, Moscow, 1966 (in Russian).

[2] V. B. Shashkoff, Applied Regression Analysis, (Multifactor Regression), Orenburg University, Orenburg, 2003, pp. 5-15 (in Russian).

[3] Y. B. Linnik, The method of least squares, and the foundations of mathematics and statistical processing of observations theory, PHYSMALIT, Moscow, 1958 (in Russian).

[4] A. R. Sumbatova, Pressure drop along the length of the pipe with a uniform steady motion [Electron. resource]. (2014) URL: http://ars.gubkin.ru/lost.htm (date of application: 10.03.2016) (in Russian)

[5] Sh. K. Gimatudinov, Handbook of oil production, Nedra, Moscow, 1983, pp. 319-325 (in Russian).

[6] A. A. Tsouprikov, Mathematical model of penetration rate for optimal management of drilling wells, Scientific Journal of KubSAU, Kuban, 2015 (in Russian). 